\title{
Różnice leksykalne w wypowiedziach zwolenników i przeciwników dopuszczalności aborcji - analiza anglojęzycznych grup w serwisie Facebook
}

\section{Lexical differences in pro-life and pro-choice Facebook discussion groups}

\author{
Klaudia Ćwierz, Ramona Cossengue Casimiro, Barbara Konat \\ InSTYTUT PSYCHOLOGII, UNIWERSYTET IM. ADAMA MICKIEWICZA \\ UL. SZAMARZEWSKIEGO 89 B, 60-568 POZNAŃ
}

\section{bkonateamu.edu.pl}

\begin{abstract}
Abstrakt
Celem niniejszego artykułu jest empiryczne ustalenie różnic leksykalnych w grupach dyskusyjnych reprezentujących odmienne postawy względem aborcji. Chcemy pokazać, w jaki sposób grupy te stosują odmienny opis świata, poprzez wybór odmiennego słownictwa. Materiał został zebrany w grupach dyskusyjnych na portalu społecznościowym Facebook, a analiza została przeprowadzona metodami statystycznymi $\mathrm{w}$ postaci uczenia maszynowego z wykorzystaniem klasyfikatorów bazujących na zestawach cech "bag of words" oraz "ngram". Zastosowano także jakościową analizę słów kluczowych.
\end{abstract}

\begin{abstract}
An individual approach to abortion is based on a perspective which is determined by a combination of personal knowledge and life values. The aim of this paper is to provide empirical analysis of lexical differences between two discussion groups representing opposing views regarding the acceptability of abortion. Our aim to show how lexical choices made by the speakers in the two groups correspond to the divergent worldviews represented in those groups. Material for the study was collected on Facebook and analysed using methods of statistical machine learning with lexical feature sets (i.e. bag-of-words and n-gram). Additional analysis for keywords in both groups was also conducted.
\end{abstract}




\section{Wstęp}

Dyskusja na temat aborcji dotyczy moralnego, prawnego i religijnego statusu przerwania ciąży. Każde stanowisko w tym temacie wzbudza pewne wątpliwości i kontrowersje, stając się przedmiotem ożywionej dyskusji także w mediach społecznościowych. Punkt sporny stanowi różnica w pojmowaniu umownej granicy, po przekroczeniu której zapłodniona komórka jajowa staje się pełnoprawnym człowiekiem. Dwa przeciwstawne stanowiska podejmowane $\mathrm{w}$ tej debacie powszechnie znane są jako ruchy "pro-choice” (ang. za wyborem) oraz „pro-life” (ang. za życiem). Przedstawiciele ruchu "pro-choice" uważają, że płód nie jest niezależnym bytem, ale (przynajmniej przez początkowy okres ciąży) stanowi część ciała matki, i podkreślają prawo kobiet do decydowania o utrzymaniu bądź przerwaniu ciąży (Rowbotham, S., 1977). Reprezentanci ruchu "pro-life" twierdzą, że już od momentu zapłodnienia powstała istota jest człowiekiem (Kirscher, W., data), który ma prawo dojrzeć i się urodzić, a uniemożliwianie jej tego (przerwanie ciąży) sprowadzają do poziomu morderstwa (źródło, data). Można uznać wobec tego, że zagadnienie aborcji jest przede wszystkim kwestią moralną, dotyczącą definicji człowieczeństwa, praw płodu, a także prawa kobiety do decydowania o własnym ciele. Celem tej pracy jest zestawienie ze sobą wypowiedzi zwolenników i przeciwników dopuszczalności aborcji w serwisie internetowym Facebook.

Zważywszy na trudny do empirycznego rozstrzygnięcia charakter, debata nad aborcją często oscyluje wokół przesłanek etycznych i emocjonalnych, a nie logicznych, czy empirycznych (Lopez, 2012). W niniejszym badaniu testujemy, czy tematy poruszane na stronach "pro-life" i "pro-choice", wzbudzające intensywny odzew użytkowników Facebooka, powodują różniące się między sobą, charakterystyczne dla każdej grupy reakcje. Stawiamy hipotezę, że wypowiedzi komentujących strony "prolife" będą różniły się leksykalnie od wypowiedzi komentujących strony "pro-choice" w stopniu, który umożliwi automatycznym klasyfikatorom trafne przyporządkowanie postów do jednej lub drugiej kategorii.

Przyjmujemy, że obie strony sporu mają odmienny językowy obraz świata (Bartmiński, 1999), który wyraża się w odmiennym doborze słów. Zakładamy też, że komentarze na stronie "pro-life" będą zawierały więcej odniesień do religii, duchowości lub natury, a komentarze ze stron "prochoice" do praw kobiet, kontroli urodzeń i planowania rodziny.

\section{Istniejące badania}

Przedmiotem niezgody w językowym aspekcie sporu nad statusem aborcji często jest nazewnictwo organizmu ludzkiego przed narodzeniem. Medyczne określenia takie jak "zarodek" (ang. embryo), czy "płód” (ang. fetus) bywają uznawane przez część zwolenników ruchu "pro-life” za obraźliwe i odczłowieczające (Getek, Cunningham, 1996). Z drugiej strony niektórzy przedstawiciele ruchu "pro-choice” mają tendencję uznawać, że 
nazywanie nowo poczętego organizmu "dzieckiem" (ang. baby) jest zbyt uczuciowe i nonsensowne.

Terminologia jest często stosowana w tej dyskusji jako narzędzie deprecjonowania przeciwstawnego podejścia. Przykładowo, określenia takie jak "pro-choice", "pro-life" kojarzą się z wartościami takimi jak wolność i prawo do życia, sugerując jednocześnie, że ich przeciwnicy muszą być "anti-choice/life" (ang. przeciw wyborowi/życiu), albo nawet "pro-coercion/death” (ang. za przymusem/śmiercią) (Holstein, Gubrium, 2008).

Związek określonych wyborów leksykalnych ze specyficznym oglądem świata był analizowany nie tylko we wspomnianym już paradygmacie Językowego Obrazu Świata. Prace z kręgu Krytycznej Analizy Dyskursu pokazują, jak używanie określonego nazewnictwa (np. nazywanie ruchu migrantów "powodzią" w Gabrielatos i Barker, 2008) może wpływać na sposób postrzegania zjawisk społecznych. Podobne stanowisko reprezentują języ koznawcy kognitywni, których tezy również mogą badane w ujęciu korpusowym (Fabiszak i Konat, 2013).

\section{Material i metody}

Materiałem poddanym analizie $\mathrm{w}$ niniejszej pracy są komentarze do postów z anglojęzycznych stron w serwisie Facebook, propagujących ruch "pro-life": I Am Pro-Life1 i National Pro-Life Alliance2, oraz pod postem ze strony ruchu "pro-choice": NARAL Pro-Choice America3. Opublikowane przez strony "pro-life" najczęściej komentowane posty dotyczyły: a. filmu kwestionującego moralny i prawny status aborcji i zachęcającego do bronienia praw nienarodzonych istot (I Am Pro-Life, 2016), oraz b. hasła głoszącego, że społeczeństwo bardziej przejmuje się ochroną środowiska niż losem obiektów aborcji (National Pro-Life Alliance, 2017). Tematyka poruszona przez najbardziej popularny post ze strony "pro-choice" dotyczyła bieżącej sytuacji kliniki wspierającej planowane rodzicielstwo (NARAL Pro-Choice America, 2017). Łącznie zebrałyśmy 1200 instancji; 600 komentarzy z kategorii "pro-life", 600 komentarzy z kategorii "prochoice”. Podzieliłyśmy bazę danych na część treningową (400 instancji, po 200 z każdej kategorii) i część testową (800 instancji, po 400 z każdej kategorii). Korpus kategorii "pro-choice" liczył 38457 słów, natomiast korpus kategorii "pro-life" 31079 słów.

1I Am Pro-Life (Dostęp 2 kwietnia 2017). [Post w serwisie Facebook]. Pobrane z: https://www.facebook.com/search/top/?q=There\%20are\%2oreally\%20 only\%2ofour\%20 way s\%20the\%2o unborn\%2odiffer\%20 from\%2otoddlers.\&init=mag_glass\&tas=0.33346 $54532434831 \&$ search_first_focus $=1492182043994$

2 National Pro-Life Alliance (2 kwietnia 2017). [Post w serwisie Facebook]. Pobrane z: https://www.facebook.com/ProLifeAlliance/photos/a.153781571335145.28267.14517035 $5529600 / 1380658641980759 /$ ?ty pe $=3$ \&theater

3 NARAL Pro-Choice America (Dostęp 2 kwietnia 2017). [Post w serwisie Facebook]. Pobrane

https://www.facebook.com/naralprochoiceamerica/posts/10155193760449321 
Za pomocą narzędzia Graph API Explorer (dostęp 2 kwietnia 2017) pobrałyśmy serie komentarzy $\mathrm{z}$ postów na wybranych stronach $\mathrm{i}$ zapisałyśmy je w formacie "json", służącym do wymiany danych. Następnie przetworzyłyśmy dane przy pomocy programu OpenRefine (dostęp 2 kwietnia 2017), co pozwoliło na wyodrębnienie z pobranego pliku samej wiadomości tekstowej. Ostatecznie uzyskałyśmy plik w formacie "txt" oraz przypisałyśmy poszczególnym instancjom etykiety $\mathrm{z}$ jedną $\mathrm{z}$ dwóch kategorii ("pro-life" lub "pro-choice"). Przez kategorię "pro-choice" rozumiemy zbiór komentarzy (instancji) odnoszących się do postu przedstawiającego poglądy zgodne $\mathrm{z}$ podejściem opowiadającym się za dopuszczeniem aborcji, natomiast kategoria "pro-life" odnosi się do zbioru komentarzy pod postem przedstawiającym poglądy zgodne $\mathrm{z}$ podejściem przeciwnym dopuszczeniu aborcji.

Analizę zebranego materiału tekstowego przeprowadziłyśmy za pomocą pakietu pakietu OpenNLP (dostęp 2 kwietnia 2017), który służy do przetwarzania danych języka naturalnego. Przy pomocy polecenia "Tokenizer ME" stokenizowałyśmy zgromadzone dane, czyli tekst został podzielony na ciąg pojedynczych tokenów (odrębnych ciągów znaków). Następnie za pomocą narzędzia "DoccatTrainer" wytrenowałyśmy model tak, aby był $\mathrm{w}$ stanie poprawnie decydować, do której z dwóch zdefiniowanych kategorii powinien przypisać wylosowane z całego korpusu zdanie. Kolejne zastosowane przez nas polecenie "DoccatEvaluator" pozwoliło na ocenę jakości klasyfikacji wyuczonej przez modele Bag of Words (BoW) oraz N-gram (przy $\mathrm{n}=2$ ). W modelu BoW tekst jest reprezentowany jako "wór" (zbiór) słów, w którym pomijane są właściwości gramatyczne i kolejność wyrazów. Z kolei model n-gram dzieli cały tekst na $\mathrm{n}$ obiektów, w których zachowana jest kolejność występujących po sobie wyrazów.

\section{Wyniki}

Ewaluacja dostarczyła informacji o osiągniętej przez modele precyzji, zwrotu, oraz miary-F. Przez precyzję (ang. precision) rozumiemy miarę, która ocenia klasyfikator na podstawie tego jak wiele sklasyfikowanych "pozytywnie" obiektów jest relewantnych. Zwrot (ang. recall) jest miarą czułości klasyfikatora, czyli tego jak wiele relewantnych obiektów zostało sklasyfikowanych "pozytywnie". Miara-F (ang. F-measure) jest próbą zrównoważenia precyzji i zwrotu. Wyznacza się ją na podstawie stosunku podwojonego iloczynu precyzji i czułości do ich sumy (Kozak, Boryczka, 2014).

\subsection{Ewaluacja klasyfikatora BoW}

Pro-life

\begin{tabular}{|l|l|}
\hline Precyzja & $\begin{array}{l}85 \% \text { instancji zostało poprawnie sklasyfikowanych jako "pro- } \\
\text { life". }\end{array}$ \\
\hline Zwrot & $\begin{array}{l}\text { z całego zbioru instancji kategorii “pro-life" udało się wydobyć } \\
68 \% \text { instancji kategorii “pro-life”. }\end{array}$ \\
\hline
\end{tabular}


\begin{tabular}{l|l}
\hline Miara-F & stosunek precyzji do zwrotu wyniósł ok. 76\%.
\end{tabular}

Pro-choice

\begin{tabular}{|l|l|}
\hline Precyzja & $\begin{array}{l}73 \% \text { instancji zostało poprawnie sklasyfikowanych jako "pro- } \\
\text { choice”. }\end{array}$ \\
\hline Zwrot & $\begin{array}{l}\text { z calego zbioru instancji kategorii “pro-choice” udało sie } \\
\text { wydobyć 88\% instancji kategorii “pro-choice”. }\end{array}$ \\
\hline Miara-F & stosunek precyzji do zwrotu wyniósł 80\%. \\
\hline
\end{tabular}

176 instancji "pro-choice" zostało sklasyfikowanych prawidłowo do kategorii "pro-choice".

64 instancje "pro-choice" zostały błędnie zaklasyfikowane jako instancje kategorii "pro-life".

136 instancji "pro-life" zostało poprawnie skategoryzowanych do kategorii "pro-life".

24 instancje "pro-life" zostały błędnie sklasyfikowane do kategorii "prochoice".

Ilość błędnych klasyfikacji dla instancji kategorii "pro-life" wyniosła 64 (32\%), natomiast dla kategorii "pro-choice" 24 (12\%) instancje.

\subsection{Ewaluacja klasyfikatora N-gram}

Pro-life

\begin{tabular}{|l|l|}
\hline Precyzja & $\begin{array}{l}72 \% \text { instancji zostało poprawnie sklasyfikowanych jako "pro- } \\
\text { life". }\end{array}$ \\
\hline Zwrot & $\begin{array}{l}\text { Z całego zbioru instancji kategorii "pro-life" udało sie } \\
\text { wydobyć ok. 57\% instancji kategorii "pro-life". }\end{array}$ \\
\hline Miara-F & Stosunek precyzji do zwrotu wyniósł ok. 63\%. \\
\hline
\end{tabular}

Pro-choice

\begin{tabular}{|l|l|}
\hline Precyzja & $\begin{array}{l}\text { 64\% instancji zostało poprawnie sklasyfikowanych jako "pro- } \\
\text { choice”. }\end{array}$ \\
\hline Zwrot & $\begin{array}{l}\text { Z całego zbioru instancji kategorii “pro-choice” udało się } \\
\text { wydobyć ok. 79\% instancji kategorii "pro-choice”. }\end{array}$ \\
\hline Miara-F & Stosunek precyzji do zwrotu wyniósł ok. 71\%. \\
\hline
\end{tabular}

157 instancji kategorii "pro-choice" zostało sklasyfikowanych prawidłowo do kategorii pro-choice.

87 instancji kategorii "pro-choice" zostało błędnie sklasyfikowanych jako instancje kategorii "pro-life".

113 instancje kategorii "pro-life" zostały poprawnie sklasyfikowane do kategorii "pro-life". 
43 instancje kategorii "pro-life" zostały błędnie sklasyfikowane do kategorii "pro-choice".

Liczba błędnych klasyfikacji dla instancji kategorii "pro-life" wyniosła 64 (32\%), natomiast dla kategorii "pro-choice" 24 (12\%) instancje.

Wyniki dla modelu stworzonego z użyciem klasyfikatora BoW okazały się być okazały się być lepsze niż $\mathrm{w}$ przypadku modelu n-gram. Klasyfikator n-gram błędnie sklasyfikowal większą liczbę instancji (niż BoW) do nieprawidłowej kategorii. W BoW trafność klasyfikacji jest wyższa od N-gram (odpowiednio $78 \%$ i $67,5 \%$ ).

1. I'm just so pissed that a person with NO experience, that did not get the most votes by MILLIONS of votes is destroying our country. This isn't right.

(tłum.: Jestem wściekły, że osoba bez doświadczenia, która nie dostała większości głosów spośród milionów niszczy nasz kraj. Tak nie powinno być.)

2. If it is true that Federal Funds are not used for abortions... what is the objection. If it's birth-control, will the Fed. Gov't outlaw prophylactics and Viagra? Informed minds want to know!!

(tlum.: Jeśli to prawda, że fundusze federalne nie są wykorzystywane do aborcji... w czym problem? Jeśli chodzi o kontrolę rodzicielstw

a, to czy rząd federalny zakaże profilaktyki i Viagry? ? Poinformowane umysty chca wiedzieć!)

3. I'm pro-Life for ME, but I'm pro-choice for any other woman because it isn't up to ANYONE but HER to decide what's best for her. And she will deal with the spiritual aspects of her decisions according to God, NOT according to MEN. EFF OFF White Male privilege asshats.

(tlum.: Jestem pro-life dla mnie samej, a pro-choice dla wszystkich inny ch kobiet, bo to niczyja sprawa, tylko kobiety by decydować co będzie dla niej najlepsze. I to ona będzie odpowiadać za duchowe aspekty swoich decyzji przed Bogiem. Nie przed ludźmi. Odczepcie się, szowinistyczne świnie.)

4. All these ppl saying abortion is fine \& asking why others haven't stepped up to give a child a home!???? Ok, why haven't you?? Let's see you adopt a child!!

(tłum.: Wszyscy ludzie, którzy mówią, że aborcja jest w porządku i pytaja dlaczego inni nie są skłonni zapewnić dziecku domu? Ok, dlaczego tego nie zrobiliście? Zobaczmy jak adoptujecie dziecko!)

Tabela 1. Instancje kategorii "pro-choice" błędnie sklasyfikowane przez predyktor jako "pro-life" $w$ modelu n-gram. 
Klasyfikator BoW również sklasyfikował błędnie Instancje kategorii "pro-choice" (przykłady 2-4) z powyższej tabeli jako "pro-life”. Dodatkowo błędnie sklasyfikowane zostały poniższe dwa przykłady.

1. Oh my God!!!! NO ONE PAYS FOR AN ABORTION EXCEPT THE PERSON/S GETTING IT! Planned Parenthood is a blessing to many How difficult is that????

(tłum.: O mój Boże! Nikt nie płaci za aborcję, poza osobą, która jej na sobie dokonuje! Organizacja Planned Parenthood jest błogosławieństwem dla wielu! Czy to takie trudne?)

2. FINALLY maybe GOD weill bless this country after 8 YEARS of $\sin$ !!!! It took 70 DAYS to DO THIS.... and you moderate republicans that voted no....hopefully your church will thow you OUT!!!

(tłum.: Nareszcie, może Bóg pobłogosławi temu krajowi po 8 latach grzechu! Dokonanie tego zajęło 70 dni.. A wy umiarkowani republikanie, którzy zagłosowaliście przeciw.. Miejmy nadzieję, że kościół was wyrzuci!)

Tabela 2. Instancje kategorï "pro-choice” błędnie sklasyfikowane przez predyktor jako "pro-life" $w$ modelu BoW.

Jak można zauważyć powyżej, instancje nr 3 z Tabeli 1. i nr 2 z Tabeli 2. są faktycznie komentarzami osób o poglądach "pro-life", które znalazły się pod postem strony "pro-choice”. Toteż gdyby grupa była bardziej jednorodna, czyli składała się wyłącznie z zadeklarowanych zwolenników danego poglądu, można by spodziewać się lepszej trafności klasyfikacji.

W celu jakościowej analizy cech leksykalnych wpływających na efektywność klasyfikatora, dokonano porównania słów kluczowych w obu próbkach dyskursu (,pro-life” i „pro-choice”). Analiza została wykonana z użyciem programu AntConc (Anthony, 2013). Słowa kluczowe to takie, które pojawiają się statystycznie istotnie częściej w jednym zbiorze tekstów (korpusie celowym) niż w innym zbiorze tekstów (korpusie referencyjnym). Słowa kluczowe zatem, w przyjętym tutaj rozumieniu nie są po prostu najczęstszymi słowami, ale tymi, które różnicują pomiędzy dwoma zbiorami tekstów (patrz Tabela 3.). Słowa kluczowe w korpusie pro-life uzyskano porównując go $\mathrm{z}$ korpusem pro-choice jako referencyjnym. Słowa kluczowe w korpusie pro-choice uzyskano porównując go z korpusem pro-life jako referencyjnym stosując miarę Log Likelihood oraz normalizując częstości na 10 ooo wystąpień4.

$4 \mathrm{~W}$ analizie słów kluczowych pominięto słowa funkcyjne (tj. przedimki, czasowniki posiłkowe, rodzajniki itp.) pozostawiając jedynie słowa leksykalne (rzeczowniki, przy miotniki, przysłówki i czasowniki). 


\begin{tabular}{|l|l|l|}
\hline Lp. & $\begin{array}{l}\text { Lista słów kluczowych w } \\
\text { korpusie pro-life }\end{array}$ & $\begin{array}{l}\text { Lista słów kluczowych w } \\
\text { korpusie pro-choice }\end{array}$ \\
\hline 1. & życie (ang. life) & kobiety (ang. women) \\
\hline 2. & Bóg (ang. god) & usługi (ang. services) \\
\hline 3. & człowiek (ang. human) & aborcje (ang. abortions) \\
\hline 4. & dzieciątko (ang. baby) & zdrowie (ang. health) \\
\hline 5. & dziecko (ang. child) & planowane (ang. planned) \\
\hline 6. & amen & rodzicielstwo(ang. parenthood) \\
\hline 7. & oddech (ang. breath) & stany (ang. states) \\
\hline 8. & zwierzęta (ang. animals) & biedny (ang. poor) \\
\hline 9. & prawda (ang. truth) & płacić (ang. pay) \\
\hline 10. & kapitał (ang. capital) & federalny (ang. federal) \\
\hline
\end{tabular}

Tabela 3. Lista stów kluczowych $w$ korpusie pro-life (z korpusem prochoice jako referencyjnym) oraz lista stów kluczowych $w$ korpusie prochoice (z korpusem pro-life jako referencyjnym).

Słowa kluczowe zaprezentowane $\mathrm{w}$ Tabeli 3. ukazują różnicę $\mathrm{w}$ centralnych ideach opisywanych $\mathrm{w}$ obu typach postaw. Dla osób komentujących na stronach „pro-life” najistotniejsze jest życie („life” na pierwszym miejscu słów kluczowych), a zaraz po nim Bóg („god” na miejscu kolejnym oraz „amen”). Dla grupy „pro-choice” na pierwszym miejscu znajduje się słowo “kobiety” („women”), a kolejne słowa wskazują na ujmowanie aborcji jako zabiegu medycznego i związanego ze zdrowiem („services”, „health”). Pozostałe słowa kluczowe ujmują aborcję w kontekście socjalnym - jako konieczność związaną z niedostatkiem („poor”, „pay”) i coś, czym powinno zajmować się państwo („states”, „federal”). Z kolei po stronie pro-life widzimy szereg pojęć związanych z zagadnieniem płodu jako czlowieka („human”, „baby”, „child”). Słowo „kapitał” („capital”) występuje w zestawieniu „kapitał ludzki” (,human capital”), natomiast prawda („truth”) w założeniach dotyczących zatajania prawdy o aborcji.

\section{Podsumowanie}

Ewaluacja jakości klasyfikatorów w modelach BoW i n-gram wykazała, że model Bag of Words okazał się dostatecznie trafny w rozpoznawaniu i przypisywaniu kategorii elementom omawianego korpusu. Trafność $\mathrm{w}$ modelu BoW wynosiła 78\%. Można zatem stwierdzić, że tematyka poruszana na stronach "pro-choice" wywołuje reakcje i wypowiedzi użytkowników, które różnią się od reakcji i wypowiedzi komentujących strony "pro-life". Klasyfikacja była mniej trafna przy wykorzystaniu modelu n-gram (67,5\%), co może świadczyć to o tym, że większe różnice językowe między kategoriami da się odnaleźć w najczęściej używanych 
przez każdą grupę słowach niż w stosowaniu konkretnych sformułowań (sekwencjach słów).

Pozwala to stwierdzić, że mówcy w obu grupach faktycznie stosują odmienne sposoby opisu świata, co wyraża się ich wyborach leksykalnych. Kiedy zwolennicy całkowitego zakazu aborcji mówią o “życiu” "Bogu” czy "dziecku”, zwolennicy liberalizacji przepisów zwracają uwagę na kwestie socjalne ("biedny"), stawiając w centrum kobietę i jej zdrowie. Dla możliwości osiągnięcia konsensusu ważnym krokiem jest dążenie do uwspólnienia pojęć i stworzenia takiego opisu świata, który będzie wspólny dla obu grup.

Kwestia prawa dopuszczalności aborcji to ciągłe poszukiwanie konsensusu, toteż rozważana jest ona jako dylemat polityczny i prawny w mediach, a także na portalach internetowych. Część osób jest przeciwna aborcji, jednak skłania się ku umożliwienia jej w szczególnych wypadkach, takich jak gwałt, czy nieprawidłowy rozwój płodu. Inni przeciwstawiają się temu rozwiązaniu, stanowczo nie zgadzając się na to, aby człowiek mógł decydować o życiu innego człowieka, który w naturalnych warunkach mógłby się narodzić i żyć jako pełnoprawna osoba. Całkowity zakaz aborcji może jednak doprowadzić do sytuacji, w której kobieta będzie skazana na ponoszenie konsekwencji cudzych wyborów i działań, albo radzenie sobie z problemami, których nie będzie w stanie udźwignąć. Z kolei dopuszczenie i upowszechnienie aborcji niesie ryzyko nadużyć $w$ przypadku niewystarczającej świadomości decydujących się na nią kobiet (wykonywanie aborcji zamiast stosowania antykoncepcji, występowanie urazów psychicznych z powodu dokonania aborcji). Nasze wyniki pokazują, że osiągnięcie porozumienia $\mathrm{w}$ tej kwestii może być utrudnione przez fakt, że obie strony sporu posługują się znacząco odmiennym słownictwem. 


\section{Bibliografia}

Anthony, L. (2013). Developing AntConc for a new generation of corpus linguists. Proceedings of the Corpus Linguistics Conference (CL 2013), July 22-26, 2013. Lancaster University, UK, pp. 14-16.

Apache OpenNLP (2017). The Apache Software Foundation. (Dostęp 2 kwietnia 2017). Strona oprogramowania: https://opennlp.apache.org/

Bartmiński, J. (1999). Językowy obraz świata. Wydaw. Uniwersytetu Marii CurieSkłodowskiej.

Gabrielatos, C., Baker P. (2008). "Fleeing, sneaking, flooding: A corpus analysis of discursive constructions of refugees and asylum seekers in the UK press, 1996-2005." Journal of English linguistics 36.1: 5-38.

Getek, K., Cunningham, M. (1996). A Sheep in Wolf's Clothing - Language and the Abortion Debate. Princeton Progressive Review.

Graph API. Facebook Platform. (Dostęp 2 kwietnia 2017). Strona platformy: https://developers.facebook.com/docs/graph-api/overview/

Holstein, J., Gubrium, J. (2008). Handbook of Constructionist Research. Guilford Press.

I Am Pro-Life (Dostęp 2 kwietnia 2017). [Post w serwisie Facebook]. Pobrane z: https://www.facebook.com/search/top/?q=There\%20are\%20really\%20only\%20 four\%20ways\%20the\%20unborn\%20differ\%2ofrom\%2otoddlers.\&init=mag glass\&tas $=0.3334654532434831 \&$ search_first_focus $=1492182043994$

Kischer, W. A human embryologist answers :"When does life begin". (Dostęp 2 kwietnia 2017). [Materiał wideo].

Fabiszak, M. , Konat, B. (2013), "Zastosowanie korpusów językowych w językoznawstwie kognitywnym”, Metodologie językoznawstwa 1:131-142.

Kozak, J., Boryczka, U. (2014). Budowa ukierunkowanych klasyfikatorów z zastosowaniem algorytmu ACDT. Systemy inteligencji obliczeniowej, Chorzów.

Lopez, R. (2012). Perspectives on Abortion: Pro-Choice, Pro-Life, and What Lies in between. European Journal of Social Sciences, 27(4), 511-517.

Mathewes-Green, F. (1996). Pro-life, pro-choice: Can we talk? Christian Century, 113.

NARAL Pro-Choice America (Dostęp 2 kwietnia 2017). [Post w serwisie Facebook]. Pobrane z: https://www.facebook.com/naralprochoiceamerica/posts/1015519376044932 1

National Pro-Life Alliance (2 kwietnia 2017). [Post w serwisie Facebook]. Pobrane z:

https://www.facebook.com/ProLifeAlliance/photos/a.153781571335145.28267.1 45170355529600/1380658641980759/?type=3\&theater

OpenRefine (2011). Google, open source community. (Dostęp 2 kwietnia 2017). Strona oprogramowania: http://openrefine.org/

Rowbotham, S. (1977). A New World for Women: Stella Browne, social feminist. pp. 66-67. 